\title{
Locational conditions and firm performance: introduction to the special issue
}

\author{
Andreas Stephan
}

Published online: 20 December 2009

(C) Springer-Verlag 2009

\section{Conceptual foundations}

Does location have an impact on firm performance? Would the same company located at different places experience a different performance, e.g., in terms of productivity or innovation output? There are good reasons to believe that, for instance, the proximity to the knowledge base is conducive for innovation efficiency, or that the availability of an excellent transport infrastructure would enhance a firm's productivity, or that a large pool of qualified labor supply contributes to a firm's competitive advantage. However, there are also good reasons to believe that a firm's location only has a minor impact on its performance; in particular, due to the existence of information technologies and modern logistical solutions.

The papers in this issue address this question. Many of the studies included are based on micro data analysis. In recent years, one can generally observe a shift from more aggregated regional level analysis to plant level analysis due to improved data availability. This particularly holds for countries, e.g. the Netherlands, Sweden, and Germany, and good examples of such studies are provided in Sternberg (1999) and Audretsch and Dohse (2007). The common theme is the analysis whether beneficial locational conditions improve firm performance. For assessing the causal impact from location on firm performance, one ideally would need a type of counterfactual

\footnotetext{
A. Stephan $(\bowtie)$

Jönköping International Business School, Jönköping, Sweden

e-mail: Andreas.Stephan@ihh.hj.se
}

\section{A. Stephan}

DIW Berlin, Berlin, Germany

A. Stephan

CESIS, Stockholm, Sweden 
outcome: place a company first in one location, then in the other location while keeping all other factors constant. Then, the difference in performance between those two locations could be attributed to the causal impact of location. However, considering that such an experiment is impossible, one alternative strategy is to compare two firms that are nearly identical in all their firm characteristics but are located in different types of regions; for example, one firm is located in an agglomerated urban area, whereas the other firm is located in a nondensely populated rural area. The difference in performance that can be observed for those two firms can be used as an estimator for the unobservable counterfactual outcome, that is, would be an estimator of the causal impact of location on performance.

This methodological consideration leads us to another important conceptional question: in practice, is it possible to observe two similar firms in different types of locations? If not, does this mean that we are comparing apples and oranges with each other? However, if the answer to this question is yes, even in this case we should be very cautious when comparing firm performance in different locations. There are several reasons why this might be a relevant phenomenon. The first is that firms might be located where the firm founder(s) wants to live. The founder(s) of a firm might not have been reflective regarding finding the best location for the firm. Therefore, the outcome of a firm's location could simply be regarded as a random event which is hardly related to locational conditions. A second reason originates from path dependence and sunk costs of location choice. Many firms are located at their site of original foundation and where they have been operating for a long period of time, and this location persistence is caused by the fact that relocation of a firm is expensive; thus, there are sunk costs in the firm's location choice. Taking into account the sunk costs of firm location, the benefits of relocation-in terms of better performance due to beneficial locational conditions at a new site-must be significantly higher than the moving costs before the firm will consider a relocation. Therefore, in microlevel data we often find that most firms do not relocate. A third explanation why firms are located in certain regions with specific locational conditions might be a result of self-selection. It is worth noting that self-selection into an advantageous location is a contrast to the first reason because in this case the firm founders deliberately have chosen locations where they expected to have good locational conditions that would fit the specific needs of their firm. Though this case is a very interesting one for the purpose of an analysis of location choice and its determinants, it should be acknowledged that this case is not suitable for estimating the causal impact of location on firm performance. On the contrary, it exemplifies that location choice should be treated as the dependent variable in the analysis. Therefore, in the context of such an analysis, location choice could be modeled as a function of certain location attributes. The last reason why location might not be treated as exogenous has been discussed recently in the literature as well (Combes et al. 2009). It also refers to selection of firms into specific locations but these studies assume for instance that selection is a result of the fact that only the best performing firms are able to survive in agglomerations. Finally, firms might base their location choice on grants offered by the (local) government (see, for instance, Devereux et al. 2007).

In contrast to existing empirical studies, the theoretical literature on location choice is large and extensive, starting with Von Thuenen's model of land usage and culminating in the models of New Economic Geography. However, many theoretical 
concepts such as different types of locational spillovers-Marshallian's versus Jacob's externalities - are difficult to capture directly in empirical studies. Due to this difficulty, some studies simply assume the existence of such effects and compare firms in agglomerations with firms in other location types (e.g., Johansson and Lööf 2008). However, a limitation of this approach is that one can obtain an estimate of the "overall" location effect that is not informative with respect to the mechanism how location in agglomeration has an effect on performance; that is, it is not revealed what exact features of location are driving the measured effect. A few recent studies use survey data and the assessments by firms regarding their locational environment (e.g., Czarnitzki and Hottenrott 2009; Eickelpasch et al. 2007). The advantage of this approach is that one can obtain a very detailed assessment of the various location attributes, ranging from proximity to suppliers and customers, research, administrative, and transport infrastructure that are important to a firm. These studies also show that, quite typically, the assessments of location conditions by firms within a region can be very heterogeneous, reflecting the specific needs of the various firms. The disadvantage of this approach is, on other hand, that the assessments by firm representatives might be biased and not reflecting the "true" location conditions in the region.

Results on the importance of location attributes for firm performance (or for attracting new firms) are rather important from the economic policy perspective. Knowing the regional factors that drive innovation success at the firm level would help to implement effective innovation policies. This goes along with the recent shift from national to regionalized innovation policies (for an overview, see Fritsch and Stephan 2005). Local innovation policies are generally regarded as more promising approaches to promote the knowledge creation of firms. Local actors and policy makers might know better which measures will help to boost the innovativeness of local firms. It should be noted, also, that certain location conditions, e.g. inter-regional transport infrastructure links, and, thereby, accessibility, are often decided at the national level, and change only slowly, sometimes over a time span of 10 or even more years.

\section{Overview of the contributions to this issue}

Most papers included in this special issue were presented at the 11th Uddevalla Symposium in Kyoto, Japan, in 2008, and one paper was presented at the 12th Uddevalla Symposium in Bari, Italy, in 2009. The first paper in this issue is "Growth of New Firms and Spatially Bounded Knowledge Externalities" by Frank van Ort and Otto Raspe; this paper uses very rich data on newly founded firms in the Netherlands from 2001 to 2006. The authors analyze how firms' survival and growth at the individual level depend on their locational environment, measured, for instance, by the presence of a university or by the presence of other R\&D intensive firms. By applying multilevel estimation methods and taking into account potential selection biases using a Heckman approach, they find that location does, indeed, affect new firm performance: $2.1 \%$ of the variance in new manufacturing firms' growth can be assigned to area-effects (for business services this impact is 1.2\%). On the other hand, more than $97 \%$ of the total variance can be attributed to between-firm variance, that is, to a firm's internal characteristics. The authors conclude from their findings that 
although the external environment explains a rather small portion of the variation in firm performance, urban context significantly contributes to firm performance after taking into account the enormous between-firm heterogeneity. On other hand, their results suggest that at the level of the firm the conventional wisdom that new firms profit from knowledge externalities does not hold for all types of firms and contexts. They, furthermore, find that knowledge externalities also affect nonsurvival.

The second paper by Christoph Grimpe and Roberto Paduelli investigates the knowledge creation in nanomaterials and its dependence on location by defining a regional knowledge production function (KPF) at the level of the 439 German districts. Nanotechnology is viewed as one of the emerging key technologies for the coming decades, and one important question, therefore, is whether the production of new knowledge in nanotechnology depends on the regional context in terms of private and public investments in R\&D as well as on the technological specialization of a region. The authors define a negative Binomial count regression model with the number of patents as a dependent variable. One important aspect of their analysis is the correlation of knowledge in space among regions. Therefore, they apply a new spatial technique, which is known as spatial filtering, in their estimation approach as an attempt to account for the spatial effects that are left unexplained, which emerge as spatial autocorrelation (SAC) in the regression residuals. They find that both public and private R\&D have a positive and significant effect on the creation of nanomaterial patents at the district level. Moreover, they also find a positive effect of the interaction term between public and private $\mathrm{R} \& \mathrm{D}$, indicating that there are benefits of co-location of public and private $R \& D$. This finding appears to be important also from an economic policy perspective.

The third paper is entitled "Locational Conditions, Cooperation, and Innovativeness: Evidence from Research and Company Spin-Offs" by Anna Lejpras and Andreas Stephan analyzes how the innovativeness of spin-offs, originating either in a research facility or from another company, is influenced by locational conditions. By using a sample of approximately 1,500 East German firms from knowledge-intensive sectors and estimating a structural equation model by applying the partial least squares method, they find that the proximity to local research institutes and universities is the most influential factor for the cooperation intensity of spin-offs, which in turn is the most important determinant for the innovativeness of a firm. Moreover, they also find that it is not the local but the nonlocal cooperation activities that are most conducive to innovativeness of research spin-offs. These results are important from a policy perspective as well. To sustain the innovativeness of established spin-offs, regional innovation policy should promote and provide incentives for firm cooperation activities, particularly with external or nonlocal partners. Furthermore, governmental R\&D subsidies should be funneled toward research spin-offs, as the results show that the impact on innovativeness of such funding is largest for this group.

The fourth paper with title "The role of spatial agglomeration in a structural model of innovation, productivity and export: a firm-level analysis" by Roberto Antonietti and Giulio Cainelli very neatly differentiates three specific forms of local externalities in their analysis: (1) localization economies (also known as MAR economies) arising from the spatial concentration of firms belonging to the same industry; (2) Jacobs's externalities which are spurred by the variety and diversity of geographically 
proximate industries and which capture knowledge spillovers from the cross-fertilization of ideas by firms operating in related or unrelated-sectors, and (3) urbanization economies which mainly involve information spillovers as local public goods, external to both firms and industry, and which are related to the size of the market and the density of the urban area in which the firm is located. Applying a structural model to a panel of 715 Italian manufacturing firms over the period 1998-2003, they find that agglomeration economies do play a role in shaping the relationship between innovation, productivity, and export performance. In particular, the results show that related variety and urbanization economies promote $\mathrm{R} \& \mathrm{D}$ and the generation of new ideas, while specialization affects the exploitation of innovation in terms of higher levels of TFP. Finally, urbanization economies do positively affect both R\&D and the propensity to export and the relative export intensity.

The fifth paper with title "Agglomeration and Productivity -Evidence from Firm-level Data" by Martin Andersson and Hans Lööf studies the relationship between agglomeration and productivity with an extensive and representative Swedish firmlevel panel data set of about 6,800 firms over the period 1997-2004 from Statistics Sweden (SCB). They address both firm heterogeneity and endogeneity issues in their estimations by applying dynamic panel data techniques. Three questions are analyzed in their paper. First, are firms that are located in larger regions more productive when controlling for attributes of individual firms? Second, is there any difference in the relationship between region size and productivity between small and large firms? Third, is there a learning effect from agglomerations, such that firms become more productive by being located in agglomerations? Regions in this study are defined as functional regions that consist of several municipalities which together form an integrated local labor market. The results of the estimations show that there is a positive relationship between the size of a region and labor productivity at the level of individual firms. This relationship holds even when controlling for several attributes of individual firms that are likely to influence the labor productivity as well. Most importantly, the results suggest that firms become more productive by being located in agglomerations. Controlling for previous productivity levels, contemporaneous productivity is higher for firms located in larger regions. Thus, the results suggest a positive learning effect. However, the role of agglomeration phenomena does not seem to have a clear relationship to firm size.

The sixth paper entitled "Who's Got the Aces Up His Sleeve? Functional Specialization of Cities and Entrepreneurship" by David Audretsch, Oliver Falck, and Stephan Heblich analyzes start-up rates in different types of cities. They differentiate between cities dominated by headquarters and service firms (urban agglomerations), those with large stand-alone production plants in one sector (industrial agglomerations), and cities with integrated smaller firms (industrial districts). Based on a data set of 71 West German planning regions over the period 1987-2000, their results confirm that there are, indeed, different dynamics across these three types of cities. Externalities from basic research laboratories in urban agglomerations and knowledge externalities in combination with experience in industrial districts support entrepreneurship. By contrast, pure production locations and cities dominated by headquarters with only administrative functions leave very few knowledge externalities that can be commercialized by new entrants in the manufacturing sector. However, service 
providers might very well find good opportunities in these headquarter-dominated cities. As entrepreneurship is generally seen as an important driver for economic growth (see for instance, Soete and Stephan 2004), these findings appear to be rather important from the economic policy perspective.

The seventh paper with title "Creativity, Talent, and Regional Wages in Sweden" by Charlotta Melander and Richard Florida discusses the factors that affect the geographic distribution of human capital. The paper develops a structural equation model of talent and creativity, and the effect that both variables have on regional wages in various industries as a measure of the level of regional development. They propose a model where the regional institutional and cultural factors affect the distribution of talent and the concentration of talent in turn affects technology and regional wage levels. Based on regional data for 81 Swedish regions, they tested the model for several definitions of talent and human capital, using both path analysis by means of partial least squares (PLS) and structural equation modeling (SEM). The former is more suitable with smaller samples, while the latter is more suitable with larger samples. The authors, however, prefer SEM over PLS as this allows for model correlations between the independent variables which is not possible when using the PLS framework. The findings of the estimations indicate that the occupational or creative class measures outperform the conventional educational attainment measure, at least in the case of Sweden. They also find that occupations in the arts and culture, which have not typically been associated with regional development, play a significant direct role in the process. They also examine three factors that are known to affect the distribution of talent and human capital: universities, amenities (i.e., service diversity), and tolerance. The findings indicate that proximity to a university plays the most important role across the board, being significant in many versions of the model, which suggests that the university is a central hub institution of the talent-driven creative economy, and is crucial for the creation of talent, technology, and regional development. The analysis further suggests that service diversity and tolerance also play significant roles in the geographic distribution of talent. Service diversity is significantly related to the distribution of conventional human capital, the creative class, creative professionals, and several permutations of the super-creative core. Tolerance is significantly related to conventional human capital as well as to arts, design, and entertainment occupations. It is important to point out that all three regional attraction factors correlate strongly with one another. This leads the authors to the conclusion that these factors do not operate in competition with one another, but rather tend to attract or affect different types of talent. Thus, they play complementary roles in the geographic distribution of talent.

The eighth paper by Mediha Sahin, Peter Nijkamp, and Roger Stough with title "Impact of Urban Conditions on Firm Performance of Migrant Entrepreneurs-A comparative Dutch-US Study" recognizes that the wealth and progress of multicultural urban regions is not only influenced by an efficient usage of traditional production factors, but also — and in particular—by social and human factors. By doing so, they create a link from locational conditions to entrepreneurship performance. Social capital, e.g., economic synergy through open multi-actor networks, cooperative modes of initiatives among stakeholders and business actors, and human capital, e.g., motivational incentives, leadership style, and locus of control, are seen as critical success 
factors for enhanced business performance in multicultural entrepreneurial regions, especially urban areas. To study these propositions, the authors apply a Data Envelopment Analysis (DEA) with indicators of business performance as output indicators and social and human capital as input indicators. This analysis, which is based on survey data of Dutch and US migrant entrepreneurs, reveals huge differences in efficiency within the migrant entrepreneurs. This paper addresses important issues, but larger or more representative data sets are needed in order to draw more general conclusions.

\section{Conclusions and outlook}

The dependent performance variables of the various studies included in this special issue are growth and survival of new firms, innovativeness, total factor productivity, labor productivity, regional patents in nanotechnology, regional start-up rates in different cities, regional wage rates, and entrepreneurial efficiencies in two cities. Taken together, the papers in this special issue support the conjecture that location is a significant factor for firm performance, which itself is decisive for performance measures at the regional level such as patents or wage rates. However, some studies report that the impact of location is not that significant when compared with other industry or firm-internal factors (see also, Badunenko et al. 2008). The fact that location should be understood as an endogenous choice by firms is not reflected in most of the current research. This opens a promising avenue for future research. Furthermore, disentangling the location effect into urbanization, agglomeration, specialization, or diversification externalities provides interesting insights into the mechanisms behind location effects. Nevertheless, concretizing the location conditions in terms of various types of proximities, infrastructures, and accessibilities appears to be important both to firm managers when it comes to location choices as well as to political decision-makers. Another major conclusion of the current research is, therefore, that different types of firms consider different types of location attributes to be important, even if they are located in the same region. Thus, a uniform approach attempting to improve locational conditions is not efficient. The heterogeneity among the firms in judging the importance of certain location attributes might also explain why the overall impact of location is not as pronounced as could be expected from the many theoretical works that have analyzed location and firm performance.

\section{References}

Audretsch DB, Dohse D (2007) Location: a neglected determinant of firm growth. Rev World Econ 143(1):79-107

Badunenko O, Fritsch M, Stephan A (2008) What drives the productive efficiency of a Firm? The importance of industry, location, R\&D, and size, Working Paper Series in Economics and Institutions of Innovation 126, Royal Institute of Technology, CESIS, Centre of Excellence for Science and Innovation Studies

Combes P-P, Duranton G, Gobillon L, Puga D, Roux S (2009) The Productivity advantages of large cities: distinguishing agglomeration from firm selection, working papers 353 . University of Toronto, Department of Economics

Czarnitzki D, Hottenrott H (2009) Are local milieus the key to innovation performance? J Reg Sci 49(1): $81-288$ 
Devereux M, Griffith R, Simpson H (2007) Firm location decisions, regional grants and agglomeration externalities. J Public Econ 91(3-4):413-435

Eickelpasch A, Lejpras A, Stephan A (2007) Hard and Soft Locational Factors, innovativeness and firm performance: an empirical test of Porter's Diamond Model at the Micro-Level, Discussion papers of DIW Berlin 723, German Institute for Economic Research, DIW Berlin

Fritsch M, Stephan A (2005) Regionalization of innovation policy-introduction to the special issue. Res Policy 34:1123-1127

Johansson B, Lööf H (2008) Innovation activities explained by firm attributes and location. Econ Innov New Technol 17(6):533-552

Soete B, Stephan A (2004) Introduction: entrepreneurship, innovation and growth. Ind Innov 11(3): 161-165

Sternberg R (1999) Innovative linkages and proximity: empirical results from recent surveys of small and medium sized firms in German regions. Reg Stud 33(6):529-540 